J Ästhet Chir 2009 2:163

DOI 10.1007/s12631-009-0043-x

Online publiziert: 23. September 2009

(c) Springer Medizin Verlag 2009

H.G. Bull, 2

${ }^{1}$ Gesellschaft für Ästhetische Chirurgie Deutschland (GÄCD), Bad Soden a. T.

${ }^{2}$ St. Josefshospital Uerdingen, Krefeld

\title{
Der erste Geburtstag vom Journal für Ästhetische Chirurgie
}

Sehr geehrte Frau Kollegin, sehr geehrter Herr Kollege,

seit der ersten Ausgabe des „Journals für Ästhetische Chirurgie", auch unter dem Namen „JÄC“ immer bekannter, ist schon wieder ein Jahr vergangen. Mit diesem Heft liegt Ihnen jetzt die fünfte Ausgabe vor.

Herzlichen Glückwunsch zum ersten Geburtstag, „J̈̈C“!

In den einzelnen Ausgaben werden jeweils Schwerpunktthemen abgehandelt und interdisziplinäre wissenschaftliche deutschsprachige Beiträge von kompetenten Autoren veröffentlicht. Daneben sollen auch ethische und medizinrechtliche Probleme der ästhetischen Chirurgie besprochen und diskutiert werden.

In der vorliegenden Ausgabe 4/2009 gibt Prof. Groß, einer der renommiertesten Medizinethiker in Deutschland, einen Beitrag zum Thema „Ästhetische Chirurgie in ethischer Sicht".

Ich bin sicher, dass es uns in der $\mathrm{Zu}$ kunft gelingen wird, die Zeitschrift nicht nur zum Fachorgan der Gesellschaft für
Ästhetische Chirurgie zu machen, sondern darüber hinaus zu einem wesentlichen und anerkannten Journal der gesamten Fachrichtung.

Ich wünsche dem Journal eine weiterhin gute Entwicklung, zum Wohl der ästhetischen Chirurgie insgesamt und der deutschen Gesellschaft im Besonderen, und Ihnen beim Lesen dieser kleinen Jubiläumsausgabe eine anregende Lektüre. Ihr



Prof. Dr. Dr. H.G. Bull

Präsident der GÄCD

\section{Korrespondenzadresse}

Prof. Dr. Dr. H.G. Bull

St. Josefshospital Uerdingen

Kurfürstenstraße 69,

47829 Krefeld

bull.mkg@stjosef.de 